Ing. USBMed, Vol. 7, No. 1, Enero-Julio 2016

\title{
Evolución en la reglamentación de las licencias ambientales en Colombia
}

\author{
Carlos A. Zárate \\ Yepes \\ Profesor asociado
}

\author{
Viviana Gil Hernández \\ Estudiante de Ingeniería \\ Administrativa
}

Norman A. Gómez
Quintero
Estudiante de Ciencia

Estudiante de
Política

Universidad Nacional de Colombia sede Medellín

\{cazarate; vigilhe; nagomezq; cjarangob\}@unal.edu.co

\author{
Carlos J. Arango \\ Bastidas \\ Ingeniero Industrial
}

(Tipo de Artículo: Revisión. Recibido el 03/12/2015. Aprobado el 20/06/2016)

Resumen. El presente artículo, pretende evidenciar los cambios que han sido efectuados sobre la legislación colombiana referida a la reglamentación de las licencias ambientales, mediante la realización de una análisis crítico y comparativo de los aspectos tanto positivos como negativos en cada una de las reformas que se han desarrollado desde la aparición del Código de recursos naturales renovables y del Medio Ambiente-Decreto 2811 de 1974, hasta el decreto 2041 de 2014.

Palabras clave. Diagnóstico ambiental de alternativas, Estudio de Impacto ambiental, Flexibilidad, Licencia Ambiental, Plan de manejo ambiental.

\section{Developments in the Regulations on Environmental Licenses in Colombia}

\begin{abstract}
This article, wants to prove the changes which have been performed about Colombia legislation that speak about environmental licenses regulation, by means of a critical and comparative analysis of those positives and negatives aspects besides of those which were admitted and regulated on every one of the reforms that have been developed from the apparition of Código de Recursos Naturales Renovables y del Medio Ambiente-Decreto 2811 of 1974 to the regulation of decree 2041 of 2014.
\end{abstract}

Keywords: Environmental Diagnosis of Alternatives, Environmental Impact, Flexibility, Environmental License, Environmental Management Plan

\section{Introducción}

Colombia en materia de legislación ambiental, ha experimentado cambios importantes durante las últimas dos décadas, éstos han estado influenciados en gran parte por las necesidades y presiones de los diferentes sectores tanto públicos como privados y comunitarios.

El presente artículo busca dar a conocer y analizar de manera crítica, los aspectos negativos y positivos que han tenido dichas variaciones en los decretos que reglamentan las licencias ambientales en Colombia.

Además se realizará un análisis cronológico y detallado de cada uno de los artículos que permita observar los cambios y las implicaciones asociadas a los mismos, posteriormente se realizaran conclusiones y recomendaciones respecto a lo analizado y a los cambios que esto implicó.

\section{Críticas a las diferentes modificaciones efectuadas al procedimiento de licenciamiento ambiental}

Colombia es un país mundialmente caracterizado por su amplia riqueza en biodiversidad y recursos naturales, sin embargo, existe inseguridad jurídica, debido a los diferentes cambios que se han producido en la legislación que regula los procedimientos para las evaluaciones y estudios previos a la solicitud de una licencia ambiental.

Los cambios que ha tenido la legislación ambiental en las últimas dos décadas, se aprecian no solo en la regulación como tal, sino, en los tiempos y la rigurosidad en los estudios, que han sido moldeados prácticamente al gusto de los sectores económicos y productivos interesados.
En principio, la institucionalidad ambiental colombiana y en general las políticas ambientales derivadas de la Constitución política de 1991, fueron tomadas como ejemplo a seguir en muchos países. A pesar de ello los gobiernos de turno, han ido deteriorando la normatividad [1].

Un claro ejemplo de ello, ha sido la flexibilización de los procedimientos para la obtención de licencias ambientales que se ha venido presentando paulatinamente desde la expedición del decreto 1753 de 1994, en el cual se presentó en forma minuciosa los requerimientos para todas las etapas de los proyectos pertenecientes a la industria de hidrocarburos. Posteriormente, mediante los Decretos 1728 de 2002, 1180 de 2003, 1220 de 2005, 2820 de 2010 y finalmente el 2041 de 2014 , que rige en la actualidad, la licencia ambiental fue debilitada.

Con respecto a la Licencia Ambiental Global se puede resaltar lo siguiente: 
Ing. USBMed, Vol. 7, No. 1, Enero-Julio 2016

Tabla 1. Análisis comparativo entre el Decreto 1753 de 1994, el Decreto 1728 de 2002 y el Decreto 1180 de 2003. Fuente: Elaboración propia

\begin{tabular}{|c|c|c|}
\hline Decreto 1753 de 1994 & Decreto 1728 de 2002 & Decreto 1180 de 2003 \\
\hline $\begin{array}{l}\text { Artículo } 5^{\circ} .- \text { Modalidades. Habrá tres } \\
\text { modalidades de Licencia Ambiental: } \\
\text { 3. Licencia Ambiental Global: La Licencia } \\
\text { Ambiental Global puede ser ordinaria o única. } \\
\text { Es de competencia exclusiva del Ministerio }\end{array}$ & $\begin{array}{l}\text { Artículo } 4^{\circ} \text {. Licencia Ambiental Global. Es la } \\
\text { autorización otorgada por la autoridad } \\
\text { ambiental competente para las obras y } \\
\text { actividades relacionadas con los proyectos } \\
\text { de explotación minera y de hidrocarburos. }\end{array}$ & $\begin{array}{l}\text { Artículo } 4^{\circ} \text {. Licencia ambiental global. Es la } \\
\text { autorización otorgada por la autoridad } \\
\text { ambiental competente para las obras y } \\
\text { actividades relacionadas con los proyectos } \\
\text { de explotación minera y de hidrocarburos. }\end{array}$ \\
\hline $\begin{array}{l}\text { de Medio Ambiente, en virtud de ella se } \\
\text { autorizan todas las obras o actividades } \\
\text { relacionadas con la explotación de campos } \\
\text { petroleros y de gas. Cuando la Licencia } \\
\text { Ambiental Global sea Ordinaria, el } \\
\text { otorgamiento de ésta no revela el beneficiario }\end{array}$ & $\begin{array}{l}\text { Para el desarrollo de cada una de las } \\
\text { actividades y obras definidas en la etapa de } \\
\text { la explotación es necesario presentar un plan } \\
\text { de manejo ambiental, conforme a los } \\
\text { términos, condiciones y obligaciones } \\
\text { establecidas en la licencia ambiental global. }\end{array}$ & $\begin{array}{l}\text { Para el desarrollo de cada una de las } \\
\text { actividades y obras definidas en la etapa de } \\
\text { la explotación es necesario presentar un plan } \\
\text { de manejo ambiental, conforme a los } \\
\text { términos, condiciones y obligaciones } \\
\text { establecidas en la licencia ambiental global. }\end{array}$ \\
\hline $\begin{array}{l}\text { de la obligación legal o reglamentaria de } \\
\text { obtener los permisos, autorizaciones o } \\
\text { concesiones que sean necesarios dentro del }\end{array}$ & $\begin{array}{l}\text { Dicho plan de manejo ambiental no estará } \\
\text { sujeto a evaluación previa por parte de la } \\
\text { autoridad ambiental competente; por lo tanto }\end{array}$ & $\begin{array}{l}\text { Dicho plan de manejo ambiental no estará } \\
\text { sujeto a evaluación previa por parte de la } \\
\text { autoridad ambiental competente; por lo tanto }\end{array}$ \\
\hline $\begin{array}{l}\text { campo de producción autorizado, ni del } \\
\text { cumplimiento de sus condiciones y } \\
\text { obligaciones específicas. Para el desarrollo } \\
\text { de cada una de las obras o actividades }\end{array}$ & $\begin{array}{l}\text { el interesado, una vez presentado este, } \\
\text { iniciará la ejecución de las obras y } \\
\text { actividades, las cuales serán objeto de } \\
\text { control y seguimiento ambiental. }\end{array}$ & $\begin{array}{l}\text { el interesado, una vez presentado este, } \\
\text { iniciará la ejecución de las obras y } \\
\text { actividades, las cuales serán objeto de } \\
\text { control y seguimiento ambiental. }\end{array}$ \\
\hline
\end{tabular}
necesario presentar un plan de manejo ambiental conforme a los términos, condiciones y obligaciones establecidas en la Licencia Ambiental Global Ordinaria.

Parágrafo 1‥- La obtención de la Licencia Ambiental Ordinaria y Global Ordinaria, es requisito previo para el otorgamiento de los permisos, autorizaciones y concesiones que se requieran conforme a la Ley o los reglamentos.

Parágrafo $2^{\circ}$.- La obtención de la Licencia Ambiental condición previa para el ejercicio de los derechos que surjan de los permisos, autorizaciones, condiciones y licencias que no sean de competencia de la autoridad ambiental.

Parágrafo $3^{\circ}$.- El término de la Licencia Ambiental será el mismo de la duración del proyecto, obra o actividad. Sin embargo, la autoridad Ambiental, de oficio a petición de parte, podrá establecer un término diferente teniendo en cuenta el estudio de impacto ambiental o la naturaleza del proyecto, obra 0 actividad.

Si se observa detenidamente la Tabla 1, se puede identificar que entre el decreto 1753 de 1994 y el decreto 1728 e 2002, proceden unas mejoras. En la primera mejora encontramos que en el decreto 1728 de 2002 la posibilidad de otorgar o no la licencia global es competencia de la autoridad ambiental competente, mientras que la anterior norma contemplaba que era competencia exclusiva del Ministerio de Medio Ambiente. En la segunda mejora encontramos que la licencia ambiental global en el decreto 1753 de 1994 buscaba regular las actividades relacionadas con la explotación de campos petroleros y de gas, mientras que en el decreto 1728 de 2002, la mejora se evidencia en que éste busca es regular las actividades relacionadas con hidrocarburos y la minería, temas que no eran contemplados en la norma anterior; y finalmente la tercera mejora que el decreto 1728 de 2002 introduce, es la no inclusión de la de la licencia ambiental ordinaria, puesto que en la práctica la que opera hoy en Colombia es la Licencia Ambiental Única, lo cual es una precisión técnica en la norma. 
Ing. USBMed, Vol. 7, No. 1, Enero-Julio 2016

Tabla 2. Análisis comparativo entre el Decreto 1220 de 2005, el Decreto 2820 de 2010 y el Decreto 2041 de 2014.

Fuente: Elaboración propia

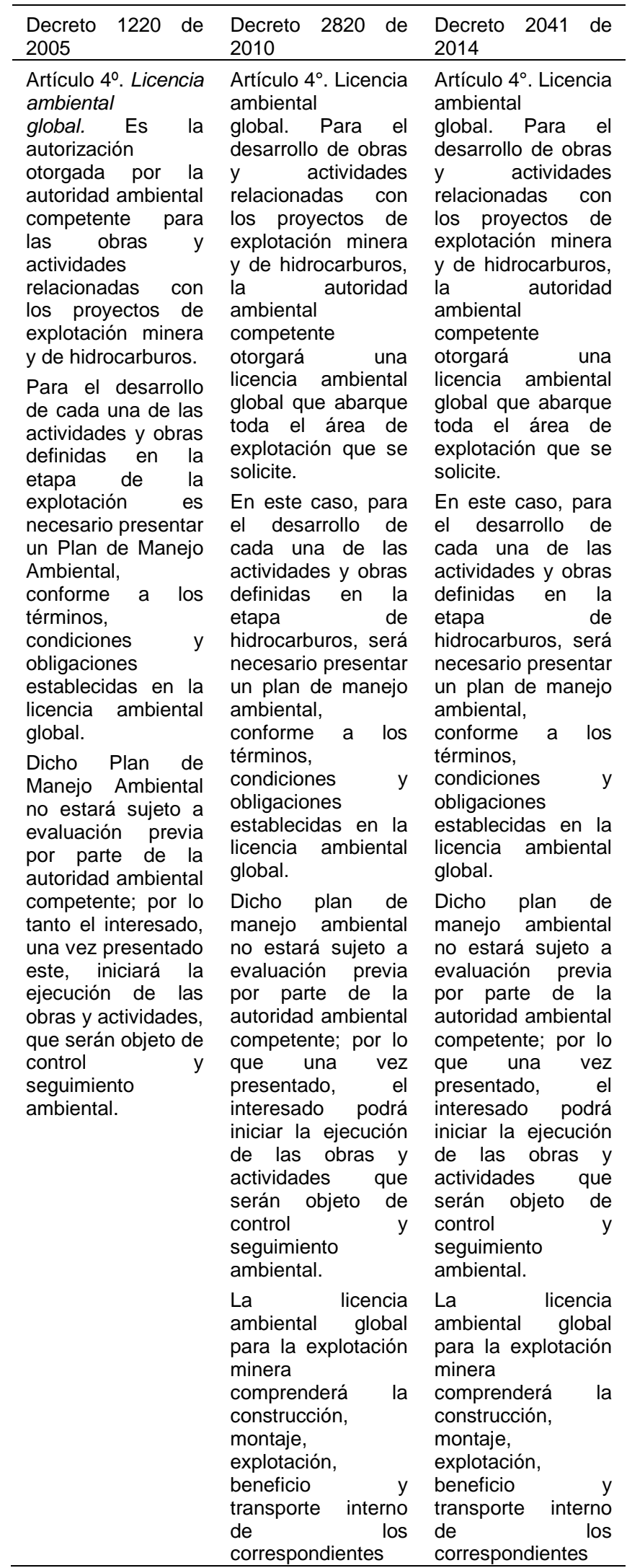

\begin{tabular}{llll}
\hline $\begin{array}{l}\text { minerales } \\
\text { materiales. }\end{array}$ & 0 & $\begin{array}{l}\text { minerales } \\
\text { materiales. }\end{array}$ & 0 \\
\hline
\end{tabular}

Respecto a la Tabla 2, los decretos 1728 de 2002, 1180 de 2003 y el 1220 de 2005 no tienen ninguna modificación entre sí, pero en el decreto 2820 de 2010 encontramos algunos cambios con respecto a los anteriores decretos. En la primera modificación hay una mejora y es más precisa, puesto que en el decreto 2820 de 2010 se menciona que cuando se otorgue la licencia global se hará por toda el área que abarque la explotación que se solicite, cuando los anteriores decretos no especificaban el área a la cual correspondía la Licencia Global. Sin embargo, el decreto 2820 también presenta algunos vacíos, en el cuarto párrafo de dicho decreto, no se toma en consideración de manera expresa el tema de la Licencia Ambiental Global para las etapas de prospección, exploración, desmonte y abandono del proyecto, como parte integral de todo el ciclo minero. En cuanto al decreto 2041 de 2014 que derogó al 2820 de 2010, contienen la misma información para la regulación de la Licencia ambiental global.

Esta situación de flexibilización de los procedimientos dejó como resultado además de estos seis decretos que cambiaron en la regulación, otros seis decretos llamados anti-trámites; tales como los Decretos 2150 de 1995, 883 de 1997, 1122 de 1999, 1892 de 1999, 266 de 2000 y por último el Decreto 500 de 2006. Todos estos cambios acontecieron en el transcurso de doce años.

A propósito, el exministro de Medio Ambiente de Colombia Manuel Rodríguez afirmó lo siguiente: "En los últimos 12 años el crecimiento del país en términos ambientales en vez de fortalecerse se ha debilitado. El saldo ha sido dejar unas entidades raquíticas a las que ahora pretendemos pedirles que corran más rápido en la carrera de convertirnos en un país moderno y competitivo" [2].

Los cambios más representativos que han sido efectuados al procedimiento de licenciamiento ambiental, son atribuibles sin lugar a duda a solicitudes y/o lobby de las partes interesadas, más que por acuerdos y debates ciudadanos, y han estado justificadas por el afán de dar cumplimiento a cambios en la demanda de productos y servicios que requieren del uso de los recursos naturales y al desarrollo de la infraestructura del país.

Con base en esto, se hace posible afirmar que el debilitamiento de las políticas e instituciones ambientales se ha dado por la visión que se tiene del crecimiento económico, la cual consiste en impulsar las exportaciones mayoritariamente, que han llevado a muchos a retirar del camino "obstáculos" como políticas y normas ambientales que según ellos solo sirven para obstruir e interferir en sus propósitos [1]. 
Estas situaciones, causales del debilitamiento de la norma, se han presentado principalmente por la dependencia que tiene la política ambiental colombiana de la voluntad y/o intereses de los mandatarios del momento; generando un ciclo de reformas con las que un gobierno busca fortalecer la política ambiental, pero los gobiernos siguientes buscan debilitar la misma por cualquier razón. Considerando que los cambios efectuados con anterioridad, no eran prioridad del momento [3, 4].

Cuando en el país se presentan estas situaciones, siempre se forman controversias sobre la necesidad de realizar cambios en el proceso de licenciamiento, debido a que generalmente los cambios realizados buscan la flexibilización de la norma y no la protección del medio ambiente como es el deber ser. Uno de los más grandes críticos que expone constantemente sus opiniones sobre el proceso y sus cambios es el senador Jorge Enrique Robledo, quien afirma que es importante que las personas involucradas en el proceso comprendan que las licencias ambientales no existen en Colombia y en el mundo para estorbarles a las empresas que hacen las cosas bien, sino para protegernos de las que lo hacen mal, por incapacidad o por mala fe, atentando contra los intereses de la sociedad [5, 6].

Algunos otros cambios, también son debidos a variaciones que ha tenido el mismo medio ambiente y que obligan a tomar medidas de adaptación, conservación y uso eficiente de los recursos de éste, puesto que la resiliencia del mismo tiende a disminuir a medida que se impacta negativamente de manera desmedida y sin tomar las acciones que controlen y reparen los efectos asociados a dichos impactos.

\section{Comparación de la normatividad que regula el proceso de licenciamiento ambiental en Colombia}

\subsection{Decreto 1753 de 1994 en comparación con el Decreto 1728 de 2002}

El 3 de agosto de 1994 se expidió el decreto 1753 de 1994. Frente a este decreto, hay que detallar que no tuvo modificaciones a la regulación de la licencia ambiental por un periodo de 8 años, tiempo considerable si lo comparamos con tiempos recientes, donde los decretos después del 1728 de 2002 no han tenido una vigencia tan duradera como el 1753 de 1994.

Posteriormente el Decreto 1728 de 2002 introdujo algunos cambios con respecto al decreto 1753 de 1994, ejemplo de esto se presenta en la Tabla 3 , donde se muestra que en el primer artículo las definiciones continuaron con la intensión de garantizar una mejor interpretación del tema ambiental asociado a las licencias ambientales, sin embargo, algunas de estas definiciones cambiaron parcial o completamente entre algunas normatividades, lo cual puede incidir en el alcance jurídico de la misma norma.

Tabla 3. Análisis comparativo entre el Decreto 1753 de 1994 y el Decreto 1728 de 2002. Fuente: Elaboración propia

\begin{tabular}{|c|c|}
\hline Decreto 1753 de 1994 & Decreto 1728 de 2002 \\
\hline $\begin{array}{l}\text { Artículo } 1^{\circ} \text { - Definiciones. Para } \\
\text { la correcta interpretación de } \\
\text { las normas contenidas en el } \\
\text { presente Decreto, se adoptan } \\
\text { las siguientes definiciones: }\end{array}$ & $\begin{array}{l}\text { Artículo } 19 \text { - Definiciones. Para } \\
\text { la correcta interpretación de las } \\
\text { normas contenidas en el } \\
\text { presente Decreto, se adoptan } \\
\text { las siguientes definiciones: }\end{array}$ \\
\hline \multirow[t]{2}{*}{$\begin{array}{l}\text { Ecosistema } \\
\text { Crítico: Es aquientalmente } \\
\text { perdido su capacidad de } \\
\text { recuperación } \\
\text { autorregulación. }\end{array}$} & $\begin{array}{l}\text { Efecto ambiental: Es la } \\
\text { consecuencia en el entorno, } \\
\text { derivada de un impacto } \\
\text { ambiental acaecido, por causas } \\
\text { de la ejecución de un proyecto, } \\
\text { obra o actividad. }\end{array}$ \\
\hline & $\begin{array}{l}\text { Terminales Portuarios de Gran } \\
\text { Calado: Son aquellos } \\
\text { terminales marítimos en los } \\
\text { cuales se puedan recibir o } \\
\text { atracar embarcaciones de diez } \\
\text { mil (10.000) o más toneladas } \\
\text { de registro bruto, que cuenten } \\
\text { con un calado igual o superior a } \\
27 \text { pies y que tengan una } \\
\text { capacidad instalada de } \\
\text { almacenamiento de más de } \\
\text { tres millones (3.000.000) de } \\
\text { toneladas al año. }\end{array}$ \\
\hline
\end{tabular}

La Tabla 3 muestra como la definición de Ecosistema Ambientalmente Crítico, establecida por el Decreto 1753 de 1994, es omitida y cambiada por Efecto Ambiental, definición presentada por el Decreto 1728 de 2002, esta última definición se expone como una consecuencia del entorno derivado de un impacto, pero no se precisa a qué clase de escala o medida se puede determinar este efecto ambiental, porque no define si el efecto es parcial o total; por el contrario, la definición que detallaba el decreto anterior indicaba que un ecosistema ambientalmente critico es aquel que ha perdido su capacidad de recuperación.

El Decreto 1728 de 2002, presenta una nueva definición, los Terminales portuarios de gran calado, lo que se considera un avance, dado que no estaba definido en el Decreto 1753 de 1994

En el Decreto 1753 de 1994, artículo 4, se consagra una gran novedad para el momento porque presenta la obligación de constituir en las actividades mineras, una póliza de garantía de cumplimiento equivalente, como máximo al $30 \%$ del costo anual de las obras de recuperación, o sustitución morfológica, que se pretendan desarrollar conforme al plan de manejo ambiental, todo como desarrollo del artículo 60 de la ley 
99 del 93. La Tabla 4 presenta los cambios generados respecto al tema.

Tabla 4. Análisis comparativo entre el Decreto 1753 de 1994 y el Decreto 1728 de 2002. Fuente: Elaboración propia

\begin{tabular}{|c|c|}
\hline Decreto 1753 de 1994 & Decreto 1728 de 2002 \\
\hline \multirow[b]{2}{*}{$\begin{array}{l}\text { Artículo 4\%.- Garantías en } \\
\text { Actividades Mineras. En } \\
\text { desarrollo del artículo } 60 \text { de la } \\
\text { Ley } 99 \text { de } 1993 \text {, toda persona } \\
\text { que desarrolle un proyecto de } \\
\text { minería a cielo abierto } \\
\text { constituirá a favor de la } \\
\text { autoridad ambiental } \\
\text { competente una póliza de } \\
\text { garantía de cumplimiento } \\
\text { equivalente, como máximo al } \\
30 \% \text { del costo anual de las } \\
\text { obras de recuperación, o } \\
\text { sustitución morfológica, que se } \\
\text { pretendan desarrollar } \\
\text { conforme al plan de manejo } \\
\text { ambiental. }\end{array}$} & $\begin{array}{l}\text { Artículo } 9^{\circ} \text {. Competencia de las } \\
\text { Corporaciones Autónomas } \\
\text { Regionales }\end{array}$ \\
\hline & $\begin{array}{l}\text { Parágrafo } 2^{\circ} \text {. Las actividades de } \\
\text { exploración minera estarán } \\
\text { sujetas a la guía ambiental que } \\
\text { para cada caso se establezca } \\
\text { conforme a la Ley } 685 \text { de } 2001 \text {; } \\
\text { el seguimiento correspondiente } \\
\text { será de competencia de las } \\
\text { Corporaciones Autónomas } \\
\text { Regionales o Grandes Centros } \\
\text { Urbanos. }\end{array}$ \\
\hline $\begin{array}{l}\text { La póliza deberá ser renovada } \\
\text { anualmente y tener vigencia } \\
\text { durante la vida útil del proyecto } \\
\text { y hasta por dos años más a } \\
\text { juicio de la autoridad } \\
\text { ambiental. }\end{array}$ & \\
\hline
\end{tabular}

En el Decreto 1728 de 2002, se evidencia que en el parágrafo 2 del artículo 9 se precisa la Autoridad Ambiental en materia minera y la necesidad de aplicar la guía ambiental, todo en armonía con lo establecido en la Ley 685 de 200, "por la cual se expide el código de minas $y$ se dictan otras disposiciones", encontrándose ya de manera específica en su artículo 280, la obligatoriedad de la póliza minero-ambiental, de la manera siguiente: Al celebrarse el contrato de concesión minera el interesado deberá constituir una póliza de garantía de cumplimiento, que ampare el cumplimiento de las obligaciones mineras $y$ ambientales, el pago de las multas y la caducidad. En el evento en que la póliza se haga efectiva, subsistirá la obligación de reponer dicha garantía" [7].

El valor asegurado es diferente al del Decreto 1753, porque lo divide de la siguiente manera: $5 \%$ del valor anual de la cuantía de la inversión para la etapa de exploración, un $5 \%$ para la etapa de construcción y montaje de la misma inversión anual, y por último un $10 \%$ para la etapa de explotación. Aunque los porcentajes de la póliza disminuyeron al pasar del $30 \%$ en el Decreto 1753 al $20 \%$ en el Decreto 1728, en el total del procedimiento de la explotación minera, se mejora en la extensión de la póliza cuando la explotación termine, dado que en el Decreto 1753, artículo 4, inciso segundo, nos dice que la póliza será renovada cada año y tendrá una vida útil durante el proyecto y hasta por 2 años más según criterio de la autoridad ambiental competente, mientras que en la

norma que la sustituyó aumentó en un año la vigencia de la póliza dándole una vida útil de 3 años. Lo que sí es evidente, es que la figura tanto de la póliza como de la definición de minería a cielo abierto desaparecen, siendo esta clase de minería sumamente perjudicial para el medio ambiente.

En la Tabla 5 se puede observar que en el decreto 1728 de 2002 existe un retroceso con respecto al decreto 1753 de 1994, como quiera que este último establece de manera expresa los casos en los que se requiere el Diagnostico Ambiental de Alternativas (DAA), mientras que su sucesor el 1728 de 2002, deja a decisión de la Autoridad Ambiental la decisión sobre si el proyecto en específico requiere o no DAA, previa consulta del interesado.

\section{Tabla 5. Análisis comparativo entre el Decreto 1753 de 1994 y el Decreto 1728 de 2002. Fuente: Elaboración propia}

\begin{tabular}{l} 
Decreto 1753 de 1994 \\
\hline Artículo $17^{\circ}$ - Procedencia. El \\
Diagnóstico Ambiental de \\
Alternativas se podrá exigir \\
para evaluar las alternativas de \\
diseño de los siguientes \\
proyectos, obras o actividades: \\
1. Aquéllas que son \\
competencia del Ministerio del \\
Medio Ambiente, excepto la \\
importación de las sustancias, \\
los materiales o los productos \\
de qué trata el numeral 8 y lo \\
que trata el numeral 12 del \\
artículo 52 de la Ley 99 de \\
1993 , además de la actividad \\
exploratoria de la minería y de \\
los hidrocarburos.
\end{tabular}

2. Construcción de presas, represas 0 embalses con capacidad entre quinientos mil (500.000) y doscientos millones (200.000.000) de metros cúbicos, y construcción de centrales generadoras de energía eléctrica entre (50.000) y cien mil (100.000) KW de capacidad instalada y el tendido de líneas de transmisión o conducción en el área de jurisdicción de la respectiva Corporación Autónoma Regional, no pertenecientes al sistema nacional de interconexión eléctrica, excepto las redes eléctricas urbanas de baja y media tensión.

3. La construcción de vías que no pertenezcan al sistema nacional de vías.

4. Construcción de distritos de riego y drenaje para áreas superiores a 1.518 hectáreas e inferiores a 20.000 hectáreas.

Decreto 1728 de 2002

Artículo 15. Exigibilidad del diagnóstico ambiental de alternativas. En los proyectos que requieran de licencia ambiental, el interesado deberá solicitar a la autoridad ambiental competente un pronunciamiento acerca de si el proyecto, obra o actividad que se pretende realizar requiere de la presentación del diagnóstico ambiental de alternativas. Lo anterior, salvo lo dispuesto por la Ley 685 de 2001.

Parágrafo. El Ministerio del Medio Ambiente 0 las Corporaciones Autónomas Regionales podrán prescindir de la exigencia del diagnóstico ambiental de alternativas, cuando se trate de ampliación, modificación, reposición, adecuación, o rehabilitación de un proyecto, obra o actividad 
Ing. USBMed, Vol. 7, No. 1, Enero-Julio 2016

Por último, esta comparación evidencia que la autoridad ambiental competente en el artículo 30, numeral 3 del Decreto 1753 de 1994, disponía que posteriormente a la presentación del EIA existía la posibilidad de requerir, al interesado en obtener la licencia ambiental, la presentación de la información adicional que ésta consideraba indispensable, sin limitación en el número de veces que se podría hacer tal requerimiento, mientras que en el Decreto 1728 de 2002, artículo 20, numeral 4, limita a la autoridad ambiental en la petición de la información, porque le exige al momento de requerir dicha información adicional, que solo se podrá hacer una sola vez, lo que para muchos es mayor seguridad jurídica pues no hace ilimitado en el tiempo la aprobación o negación de las licencias ambientales, pero para otros se constituye en una limitante al papel de evaluación, seguimiento y control que deben realizar las Autoridades Ambientales; además de esto, también les reduce el plazo de 60 días para el estudio, a 30 días en el Decreto 1728 de 2002, tal cual lo muestra la Tabla 6.

Tabla 6. Análisis comparativo entre el Decreto 1753 de 1994 y el Decreto 1728 de 2002. Fuente: Elaboración propia

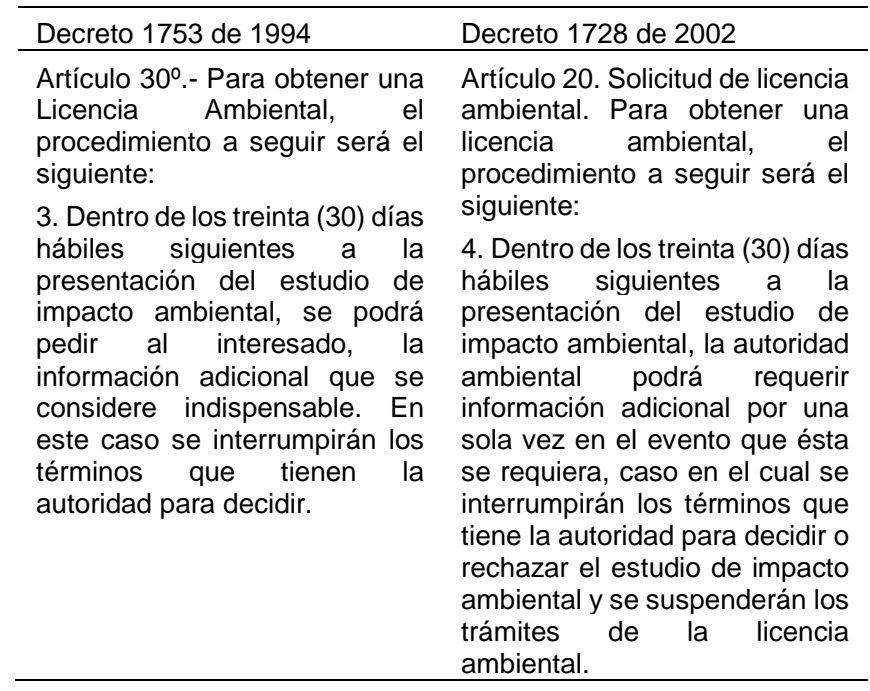

En términos de avances, encontramos que en el Decreto 1728 de 2002, aparece la definición de Terminales portuarios de gran calado como se mencionó en el comienzo de este artículo, lo que es un avance si tenemos en cuenta lo que estos proyectos significan para el desarrollo del país y sus regiones en los próximos 30 años.

Se introduce también en las definiciones, el concepto de vulnerabilidad ambiental, la cual tiene una leve similitud con la definición de "Ecosistema ambiental sensible" del Decreto 1753 de 1994. Aparece en el Decreto 1753 de 1994 la figura de licencia ambiental única, término que no se presenta en el Decreto 1728 de 2002, ya que se asume que "ningún proyecto, obra o actividad requerirá más de una licencia ambiental', lo cual es más técnico ambiental y jurídicamente con respecto a lo que establecía la anterior licencia ambiental ordinaria, evitándose de esta forma posibles contradicciones al momento de otorgar los diferentes permisos y autorizaciones que se debían tramitar para el otorgamiento de una licencia ambiental.

\subsection{Decreto 1728 de 2002 en comparación con el Decreto 1180 de 2003}

El 10 de mayo del año 2003 se expidió el Decreto 1180, el cual derogó al Decreto 1728 de 2002. Este decreto introdujo algunos cambios que se consideran positivos porque permiten un mejor control y avancen en el proceso de licenciamiento ambiental. En ambos decretos, el artículo 2 hace mención de las autoridades ambientales, sin embargo, con la promulgación del Decreto 1180, aparecen tres (3) nuevos distritos con competencias ambientales, los cuales fueron creados bajo la ley 768 de 2002. La Tabla 7 presenta el cambio generado en la ley.

\section{Tabla 7. Análisis comparativo entre el Decreto 1728 de 2002 y el Decreto 1180 de 2003. Fuente: Elaboración propia}

\begin{tabular}{|c|c|}
\hline Decreto 1728 de 2002 & Decreto 1180 de 2003 \\
\hline $\begin{array}{l}\text { Artículo } 2^{\circ} \text { Autoridades } \\
\text { ambientales competentes. Son } \\
\text { autoridades competentes para } \\
\text { el otorgamiento de licencia } \\
\text { ambiental, conforme a la ley y al } \\
\text { presente decreto, las } \\
\text { siguientes: }\end{array}$ & $\begin{array}{l}\text { Artículo } 2^{\circ} \text {. Autoridades } \\
\text { ambientales competentes. Son } \\
\text { autoridades competentes para } \\
\text { el otorgamiento de licencia } \\
\text { ambiental, conforme a la ley y al } \\
\text { presente decreto, las } \\
\text { siguientes: }\end{array}$ \\
\hline $\begin{array}{l}\text { I. El Ministerio del Medio } \\
\text { Ambiente. }\end{array}$ & $\begin{array}{l}\text { 1. El Ministerio de Ambiente, } \\
\text { Vivienda y } \\
\text { Territorial. }\end{array}$ \\
\hline $\begin{array}{l}\text { 2. Las Corporaciones } \\
\text { Autónomas Regionales y las de } \\
\text { Desarrollo Sostenible. }\end{array}$ & $\begin{array}{l}2 . \quad \text { Las Corporaciones } \\
\text { Autónomas Regionales y las de } \\
\text { Desarrollo Sostenible. }\end{array}$ \\
\hline \multirow[t]{2}{*}{$\begin{array}{l}\text { 3. Los Municipios, Distritos y } \\
\text { Áreas Metropolitanas cuya } \\
\text { población urbana sea igual o } \\
\text { superior a un millón de } \\
\text { habitantes dentro de su } \\
\text { perímetro urbano. }\end{array}$} & $\begin{array}{l}\text { 3. Los municipios, distritos y } \\
\text { áreas metropolitanas cuya } \\
\text { población urbana sea superior } \\
\text { a un millón de habitantes dentro } \\
\text { de su perímetro urbano }\end{array}$ \\
\hline & $\begin{array}{l}\text { 4. Las autoridades ambientales } \\
\text { creadas mediante la Ley } 768 \text { de } \\
2002\end{array}$ \\
\hline
\end{tabular}

Los Distritos con competencias ambientales que incluye el Decreto 1180 de 2003 son: El Distrito de Cartagena, Santa Marta y Barranquilla, los cuales según el decreto, ejercerán dentro del perímetro urbano, las mismas funciones atribuidas a las Corporaciones Autónomas Regionales en lo que fuere aplicable al medio ambiente urbano, similar a lo establecido en el artículo 66 de la Ley 99 de 1993

Al igual que se mencionan nuevas entidades con competencias ambientales, también se tiene en cuenta los proyectos o actividades que son ejecutados en 
zonas de humedales, que cuando ocurra tal caso, el dueño del proyecto deberá enviar una solicitud previa al Ministerio de Ambiente, Vivienda y Desarrollo Territorial (MAVDT) donde se evalúe la solicitud y determine la posibilidad de la aprobación o negación de la licencia. El tema de riesgos también es considerado en el decreto 1180 en su artículo 13 y es presentado en la Tabla 8.

Tabla 8. Análisis comparativo entre el Decreto 1728 de 2002 y el Decreto 1180 de 2003. Fuente: Elaboración propia

\begin{tabular}{|c|c|}
\hline Decreto 1728 de 2002 & Decreto 1180 de 2003 \\
\hline $\begin{array}{l}\text { Artículo 14. Objetivo del } \\
\text { diagnóstico ambiental de } \\
\text { alternativas. El diagnóstico } \\
\text { ambiental de alternativas } \\
\text { incluirá información sobre la } \\
\text { localización y características } \\
\text { del entorno geográfico, } \\
\text { ambiental y social de las } \\
\text { alternativas del proyecto, obra } \\
\text { o actividad y de las posibles } \\
\text { soluciones de control y } \\
\text { mitigación para cada una de } \\
\text { ellas. }\end{array}$ & $\begin{array}{l}\text { Artículo 13. Objetivo del } \\
\text { diagnóstico ambiental de } \\
\text { alternativas. Tendrá como } \\
\text { objetivo suministrar la } \\
\text { información para evaluar y } \\
\text { comparar las diferentes } \\
\text { opciones, que presente el } \\
\text { peticionario, bajo las cuales sea } \\
\text { posible desarrollar un proyecto, } \\
\text { obra o actividad, con el fin de } \\
\text { optimizar y racionalizar el uso } \\
\text { de los recursos naturales y } \\
\text { evitar o minimizar los riesgos, } \\
\text { efectos e impactos negativos } \\
\text { que puedan provocarse. }\end{array}$ \\
\hline
\end{tabular}

En dicho artículo se menciona que el objetivo del DAA no solo es presentar opciones de alternativas bajo las cuales se pueda desarrollar el proyecto, sino también, evitar y minimizar los riesgos y efectos negativos que pueda ocasionar el proyecto.

Uno de los grandes avances que generó el Decreto 1180 , fue que brindó claridad sobre qué requisitos y autorizaciones se necesitan para cada tipo de proyecto y cuál es la autoridad que los regula, tanto así, que precisa en su artículo 17, parágrafo 2 que cuando un proyecto es minero se debe regir por el artículo 282 de la Ley 685 del 2001 - Código de Minas. En este mismo artículo, se determinó que el MAVDT tenía un plazo máximo de 15 días para solucionar los conflictos de competencias que se dan entre las autoridades y determinar cuál de todas es la competente; este tema no era mencionado en el anterior decreto.

Como se mencionó, la promulgación del 1180 no solo trajo mejoras, sino también cambios que generaron un retroceso en la norma.

Desde el comienzo de la norma se detectan cambios significativos, por ejemplo en el artículo 1 que en ambos decretos refiere a las definiciones, se observan los siguientes cambios presentados en la Tabla 9.

En este artículo se presentaron varios cambios, entre los cuales se puede mencionar que las definiciones presentadas en el Decreto 1728 de 2002 son más completas, debido a que presentan la definición de Efecto Ambiental y de Vulnerabilidad ambiental, las cuales son omitidas en el decreto 1180 de 2003; sin embargo, la definición del término Impacto ambiental se presenta más completa en el decreto 1180 de 2003. Adicional a esto, se identifica una variación en el término Terminales Portuarios de Gran Calado, porque en el Decreto 1180 de 2003 es definido como Puertos marítimos de gran calado, en este sentido, los conceptos difieren, porque una terminal portuaria abarca no solo las instalaciones del puerto, sino también las áreas de depósito transitorio y las vías internas de transporte.

Tabla 9. Análisis comparativo entre el Decreto 1728 de 2002 y el Decreto 1180 de 2003. Fuente: Elaboración propia

\begin{tabular}{ll}
\hline Decreto 1728 de 2002 & Decreto 1180 de 2003 \\
\hline Artículo $1^{\circ}$. Definiciones. Para & Artículo $1^{\circ}$. Definiciones. Para \\
la correcta interpretación de las & la correcta interpretación de las \\
normas contenidas en el & normas contenidas en el \\
presente Decreto, se adoptan & presente decreto, se adoptan \\
las siguientes definiciones: & $\begin{array}{l}\text { las siguientes definiciones: } \\
\text { Evaluación de riesgo }\end{array}$ \\
Efecto ambiental & Impacto ambiental \\
Evaluación de riesgo & Medidas de compensación \\
Impacto ambiental & Medidas de corrección \\
Medidas de compensación & Medidas de mitigación \\
Medidas de corrección & Medidas de prevención \\
Medidas de mitigación & Plan de Manejo Ambiental \\
Medidas de prevención & Proyecto, obra o actividad \\
Plan de Manejo Ambiental & Puertos marítimos de gran \\
Proyecto, obra o actividad & calado \\
Terminales Portuarios de Gran & Términos de referencia \\
Calado & \\
Términos de referencia & \\
Vulnerabilidad ambiental & \\
\hline
\end{tabular}

Otro cambio se dio a nivel de los tiempos que tienen las autoridades y los beneficiarios de la licencia para expedir o entregar documentación. Además, se identifica un cambio en el tiempo que tiene el Ministerio para determinar cuál es la autoridad competente en evaluar un tipo de proyecto. A continuación la Tabla 10 presentan estas dos situaciones:

Como se puede observar en la Tabla 10, en el Decreto 1180 de 2003, a la autoridad ambiental se le redujo el plazo para expedir los Términos de Referencia (TdR) a 6 meses, plazo que en el decreto 1728 de 2002 era de 12 meses, esta reducción en el tiempo es un avance puesto que le permite a la autoridad ambiental competente actualizar y expedir los $\mathrm{TdR}$ en un menor tiempo, puede brindar seguridad jurídica a las empresas y ser posiblemente más agiles al momento de su evaluación y otorgamiento.

Tabla 10. Análisis comparativo entre el Decreto 1728 de 2002 y el Decreto 1180 de 2003. Fuente: Elaboración propia

Decreto 1728 de 2002

Decreto 1180 de 2003 
Ing. USBMed, Vol. 7, No. 1, Enero-Julio 2016

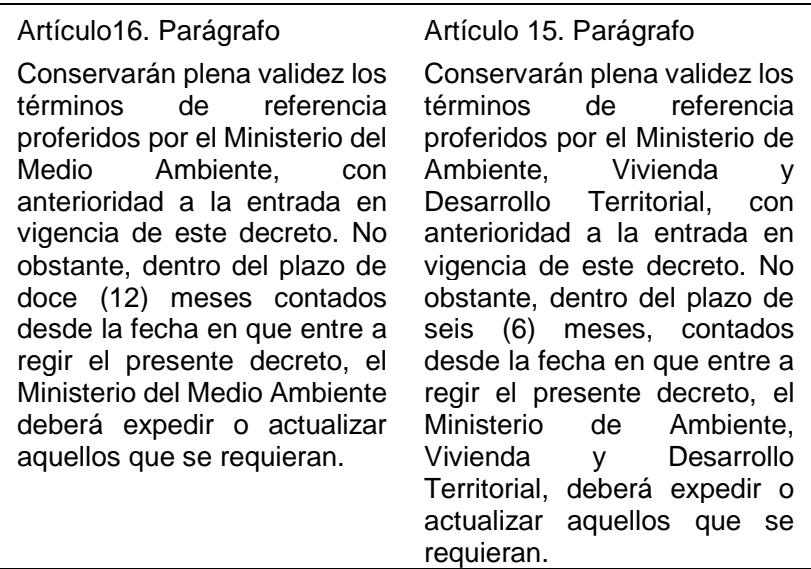

Como se puede observar en la Tabla 11, hay variación en el plazo para la solicitud de la licencia.

Tabla 11. Análisis comparativo entre el Decreto 1728 de 2002 y el Decreto 1180 de 2003. Fuente: Elaboración propia

\begin{tabular}{|c|c|}
\hline Decreto 1728 de 2002 & Decreto 1180 de 2003 \\
\hline $\begin{array}{l}\text { Artículo } 13 \text { Parágrafo. Para los } \\
\text { efectos de lo dispuesto en este } \\
\text { Artículo, la autoridad ambiental } \\
\text { a la cual se formule la solicitud } \\
\text { de licencia ambiental, si } \\
\text { considera que existe colisión o } \\
\text { concurrencia de competencias } \\
\text { sobre el proyecto, obra o } \\
\text { actividad, pondrá en } \\
\text { conocimiento del Ministerio del } \\
\text { Medio Ambiente dicha } \\
\text { situación, para que designe } \\
\text { dentro de los treinta (30) días } \\
\text { hábiles siguientes a una de las } \\
\text { autoridades ambientales } \\
\text { competentes, adelantar el } \\
\text { responsable de adela } \\
\text { procedimiento para el } \\
\text { otorgamiento de la licencia } \\
\text { ambiental. }\end{array}$ & $\begin{array}{l}\text { Artículo } 12 \text { Parágrafo. Para los } \\
\text { efectos de lo dispuesto en este } \\
\text { artículo, la autoridad ambiental } \\
\text { a la cual se formule la solicitud } \\
\text { de licencia ambiental o el } \\
\text { interesado, si considera que } \\
\text { existe colisión o concurrencia } \\
\text { de competencias sobre el } \\
\text { proyecto, obra o actividad, } \\
\text { pondrá en conocimiento del } \\
\text { Ministerio de Ambiente, } \\
\text { Vivienda y Desarrollo } \\
\text { Territorial, dicha situación, para } \\
\text { que este designe dentro de los } \\
\text { quince (15) días hábiles } \\
\text { siguientes a una de las } \\
\text { autoridades ambientales } \\
\text { competentes, de adelantar el } \\
\text { responsable de ala } \\
\text { procedimiento para el } \\
\text { otorgamiento de la licencia } \\
\text { ambiental. }\end{array}$ \\
\hline
\end{tabular}

Anteriormente el ministerio contaba con 30 días para designar una autoridad competente, ahora con el 1180 éste tiempo se redujo a 15 días. Tiempo que en ocasiones puede no ser suficiente para realizar los estudios correspondientes o tomar las decisiones adecuadas. Adicional a esto, en el 1180 no se indican con precisión ciertos temas o cláusulas que el decreto anterior si tenía en cuenta, por ejemplo, el Decreto 1728 en su artículo 25 expresa: "Sin la autorización de la autoridad ambiental competente la cesión no producirá efecto alguno y en consecuencia el cedente continuará siendo responsable de todas las obligaciones $y$ condiciones contenidas en la licencia ambiental'; es decir, cuando el beneficiario de la licencia ambiental desee ceder o traspasar los derechos y obligaciones adquiridas por medio de la licencia, éste deberá solicitar autorización previa con la aceptación del cesionario (persona a la cual se le traspasa o ceden los derechos y obligaciones) a la autoridad ambiental competente. La omisión de esta información genera confusión entre los beneficiarios, debido a que no se esclarece que no siempre se puede realizar la cesión de la licencia.

Por otro lado, el Decreto 1180 le quitó importancia a las zonas de manejo especial, porque en este decreto no se hace énfasis en este tema, solo se menciona en el artículo 9 que "cuando los proyectos señalados en el presente artículo pretendan ser desarrollados en humedales designados por el gobierno nacional para ser incluidos en la lista de humedales de importancia internacional, se requerirá concepto previo por parte del MAVDT.", es importante que al igual que en el Decreto 1728 se exprese en un artículo aparte, en qué casos es prohibido otorgar la licencia ambiental y en qué lugares está restringido la realización de proyectos. Éste tema aunque no es excluido por completo, no se le da la relevancia y claridad que debería tener, puesto que estos sitios forman parte de nuestro patrimonio natural.

De igual manera se consagraron artículos, como el que se presenta en la Tabla 12, que buscaron debilitar la norma y flexibilizarla.

Se observa que el Decreto 1180 agrega una restricción que dice que se requiere licencia ambiental para el transporte de hidrocarburos gaseosos que tengan longitudes mayores de $10 \mathrm{Km}$, esta restricción antes no estaba, es decir, a cualquier distancia a la que se estuviera del campo de explotación se requería obtener la licencia, ahora la ley es más flexible, situación que implica un retroceso notorio.

Finalmente, el Decreto 1728 de 2002 en el artículo 20 inciso 3 , se refiere a la obligación del peticionario de la licencia ambiental de efectuar el pago por costos de servicios por el concepto de la evaluación ambiental. Este análisis es presentado en la Tabla 13.

Tabla 12. Análisis comparativo entre el Decreto 1728 de 2002 y el Decreto 1180 de 2003. Fuente: Elaboración propia

\begin{tabular}{lll}
\hline Decreto 1728 de 2002 & Decreto 1180 de 2003 \\
\hline Artículo 8 Competencia del & Artículo 8 Competencia del \\
Ministerio del Medio Ambiente. & Ministerio del Medio Ambiente. \\
Numeral d) El transporte y & Numeral d) El transporte y \\
conducción de hidrocarburos & conducción de hidrocarburos \\
líquidos que se desarrollen por & líquidos que se desarrollen por \\
fuera de los campos de & fuera de los campos de \\
explotación que impliquen la & explotación que impliquen la \\
construcción y montaje de & construcción y montaje de \\
infraestructura de líneas de & infraestructura de líneas de \\
conducción con diámetros & conducción con diámetros \\
iguales o superiores a 6 & iguales o superiores a 6 \\
pulgadas (15.24 cm) y el pulgadas (15.24 cm), y el \\
transporte de hidrocarburos & transporte de hidrocarburos \\
gaseosos que se desarrollen & gaseosos que se desarrollen \\
por fuera de los campos de & por fuera de los campos de \\
explotación cuyas presiones de & explotación y que reúnan las \\
operación sean superiores a 28 & siguientes condiciones: \\
bares (400 psi), incluyendo & longitudes mayores de diez (10) \\
estaciones de bombeo y/o kilómetros, diámetros mayores \\
\hline
\end{tabular}


reducción de presión y la correspondiente infraestructura de almacenamiento y control de flujo. a seis (6) pulgadas y presión de operación superior a veintiocho (28) bares (400 psi), incluyendo estaciones de bombeo y/o reducción de presión y la correspondiente infraestructura de almacenamiento y control de flujo.

Tabla 13. Análisis comparativo entre el Decreto 1728 de 2002 y el Decreto 1180 de 2003. Fuente: Elaboración propia

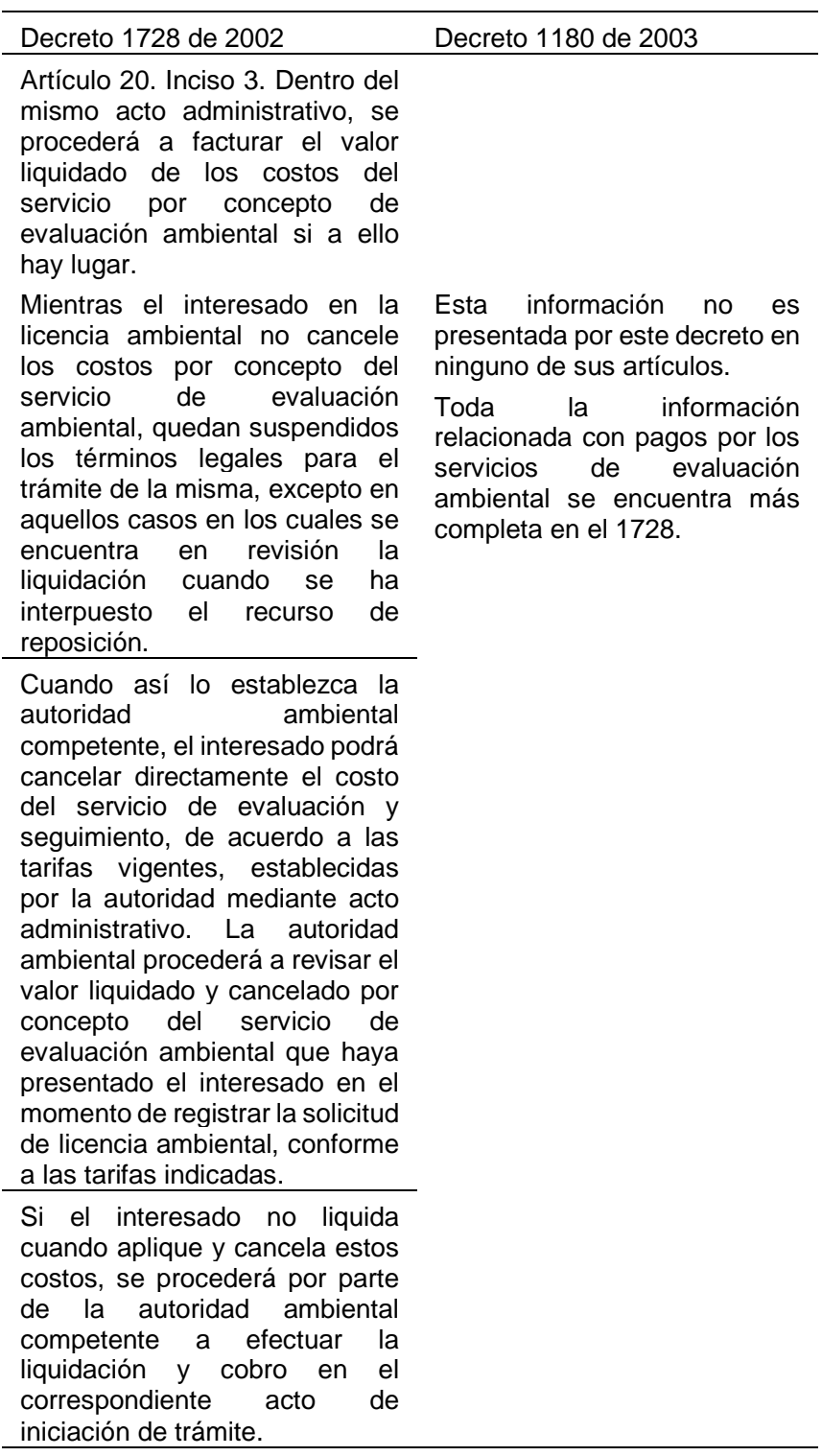

\subsection{Decreto 1180 de 2003 en comparación con el Decreto 1220 de 2005}

Los cambios que se dieron a nivel de licenciamiento ambiental durante el 2003 y el 2005 en términos generales se puede afirmar que fueron positivos, porque aunque no fueron muchos, se obtuvieron algunas exigencias adicionales y se incluyeron nuevos temas de gran importancia para todo el procedimiento de licenciamiento, seguimiento y control.
Inicialmente, el Decreto 1220 de 2005 agrega en alguno de los artículos, información que aunque no genera cambios, es de gran importancia porque permite claridad en muchos de los temas del decreto; por ejemplo en su artículo 11, que corresponde al artículo 12 del Decreto 1180, habla sobre que el Ministerio es el responsable de definir cuál es la autoridad encargada de otorgar la licencia, y que el beneficiario deberá cancelar las tasas ambientales a la autoridad ambiental en cuya jurisdicción se haga el uso, aprovechamiento y/o vertimiento respectivo. Además, en su artículo 15, afirma la existencia de un Manual de Evaluación. Esta información es presentada a continuación en la Tabla 14.

Tabla 14. Análisis comparativo entre el Decreto 1180 de 2003 y el Decreto 1220 de 2005. Fuente: Elaboración propia

\begin{tabular}{|c|c|}
\hline Decreto 1180 de 2003 & Decreto 1220 de 2005 \\
\hline \multirow[t]{2}{*}{$\begin{array}{l}\text { Esta información no fue } \\
\text { suministrada por este Decreto }\end{array}$} & $\begin{array}{l}\text { Artículo 15. Del manual de } \\
\text { evaluación. Para la } \\
\text { evaluación de los estudios } \\
\text { ambientales, las autoridades } \\
\text { ambientales adoptarán los } \\
\text { criterios generales definidos } \\
\text { en el manual de evaluación } \\
\text { que expedirá el Ministerio de } \\
\text { Ambiente, Vivienda y } \\
\text { Desarrollo Territorial dentro } \\
\text { de los seis (6) meses } \\
\text { siguientes a la publicación de } \\
\text { este decreto. }\end{array}$ \\
\hline & $\begin{array}{l}\text { Artículo 34. Del manual de } \\
\text { seguimiento. Para el } \\
\text { seguimiento de los proyectos, } \\
\text { obras o actividades objeto de } \\
\text { licencia ambiental o Plan de } \\
\text { Manejo Ambiental, las } \\
\text { autoridades ambientales } \\
\text { adoptarán los criterios } \\
\text { definidos en el manual de } \\
\text { seguimiento que expedirá el } \\
\text { Ministerio de Ambiente, } \\
\text { Vivienda y Desarrollo } \\
\text { Territorial dentro de los seis } \\
\text { (6) meses siguientes a la } \\
\text { publicación de este decreto. }\end{array}$ \\
\hline
\end{tabular}

El Manual de Evaluación, debe ser implementado por parte de las autoridades para la evaluación de los estudios ambientales; de la misma manera como se muestra en la Tabla 12, en el artículo 34 se menciona el Manual de Seguimiento, el cual permite monitorear y controlar los proyectos, obras o actividades objeto de licencia ambiental o PMA; la expedición de ambos manuales es responsabilidad del MAVDT, quien debe hacerlo dentro de los seis (6) meses siguientes a la publicación del decreto; información que no se presenta en el Decreto 1180 de 2003.

Por otro lado, incluye la siguiente información en sus artículos 16, 18 y 19, los cuales hacen alusión a temas del DAA; en el artículo 16 especifica que en las diferentes opciones presentadas en el DAA por el 
Ing. USBMed, Vol. 7, No. 1, Enero-Julio 2016

beneficiario de la licencia, se deberán tener en cuenta aspectos como: el entorno geográfico y sus características ambientales y sociales, un análisis comparativo de los efectos y riesgos inherentes a la obra o actividad, y de las posibles soluciones y medidas de control y mitigación para cada una de las alternativas. Seguidamente, en el artículo 18, el cual trata sobre el contenido que debe tener un DAA, adiciona 3 pasos, los cuales son de suma importancia para obtener los resultados esperados por el diagnóstico, estos pasos son: 1) Identificación de las comunidades y de los mecanismos utilizados para informarles sobre el proyecto, obra o actividad; 2) Selección y justificación de la mejor alternativa y 3) Un análisis costo-beneficio ambiental de las alternativas.

Finalmente, en su artículo 19, menciona que el procedimiento completo no solo consiste en presentar el DAA, sino que la autoridad debe responsabilizarse de la verificación de la información, de tal manera que determine si ésta es suficiente, verídica y que cumple con todos los parámetros exigidos por la ley. Esta información sobre la verificación, no solo se presenta en este artículo, sino también en el 21 , donde presenta el procedimiento que debe seguir la autoridad para la verificación de todos los EIA.

Un cambio significativo se presenta en el artículo 3 del decreto 1220 de 2005, pues retoma la definición de Licencia ambiental que se presentó 11 años atrás en el decreto 1753 de 1994, la Tabla 15 muestra este cambio.

TABLA 15. Análisis comparativo entre el Decreto 1180 de 2003 y el Decreto 1220 de 2005. Fuente: Elaboración propia

\begin{tabular}{|c|c|}
\hline Decreto 1180 de 2003 & Decreto 1220 DE 2005 \\
\hline $\begin{array}{l}\text { Artículo } 3^{\circ} \text {. Concepto y alcance } \\
\text { de la licencia ambiental. La } \\
\text { licencia ambiental es la } \\
\text { autorización que otorga la } \\
\text { autoridad ambiental } \\
\text { competente para la ejecución } \\
\text { de un proyecto, obra o } \\
\text { actividad, la cual sujeta al } \\
\text { beneficiario de ésta, al } \\
\text { cumplimiento de los requisitos, } \\
\text { términos, condiciones y } \\
\text { obligaciones que la misma } \\
\text { establezca en relación con la } \\
\text { prevención, compensación y } \\
\text { corrección, compen, } \\
\text { manejo de los efectos } \\
\text { ambientales del proyecto, obra } \\
\text { o actividad autorizada }\end{array}$ & $\begin{array}{l}\text { Artículo } 3 \text {. Concepto y alcance } \\
\text { de la licencia ambiental. La } \\
\text { licencia ambiental, es la } \\
\text { autorización que otorga la } \\
\text { autoridad ambiental } \\
\text { competente para la ejecución } \\
\text { de un proyecto, obra o } \\
\text { actividad, que de acuerdo con } \\
\text { la ley y los reglamentos pueda } \\
\text { producir deterioro grave a los } \\
\text { recursos naturales renovables } \\
\text { o al medio ambiente o introducir } \\
\text { modificaciones considerables o } \\
\text { notorias al paisaje; la cual } \\
\text { sujeta al beneficiario de esta, al } \\
\text { cumplimiento de los requisitos, } \\
\text { términos, condiciones y } \\
\text { obligaciones que la misma } \\
\text { establezca en relación con la } \\
\text { prevención, mitigación, } \\
\text { corrección, compensación y } \\
\text { manejo de los efectos } \\
\text { ambientales del proyecto, obra } \\
\text { o actividad autorizada. }\end{array}$ \\
\hline
\end{tabular}

Como lo expresa la Tabla anterior, el Decreto 1220 de 2005 retoma la definición de licencia ambiental que se había estipulado casi 10 años atrás con el Decreto 1753 de 1994; entre estos dos decretos, la definición variaba en que éstas no mencionaban el concepto de "deterioro grave a los recursos naturales renovables o al medio ambiente 0 introducir modificaciones considerables o notorias al paisaje". Esta información es muy importante, y por esto se reincorpora, lo cual hace necesario como en debates anteriores que se defina claramente el alcance del término de deterioro grave 0 modificaciones considerables, para una adecuada gestión hacia el futuro.

De igual forma, este decreto hace exigencias adicionales para la entrega del EIA, exigencias que permiten la obtención de más información, por consiguiente un conocimiento más detallado del proyecto y la zona donde se pretende realizar; estas exigencias se basan principalmente en facilitar información sobre la compatibilidad del proyecto con los usos del suelo establecidos en el POT, y la Identificación de las comunidades y de los mecanismos utilizados para informarles sobre el proyecto, obra o actividad.

El decreto expone además, el cobro que deben hacer las autoridades ambientales por motivo de las labores de seguimiento de la licencia y el PMA, donde los recursos recaudados sólo podrán ser destinados para esa actividad y que es obligación de la autoridad que otorgó la licencia o exigió el PMA hacerse cargo del seguimiento de las diferentes etapas en que se divide el proyecto, incluyendo la de abandono o desmantelamiento. Adicionalmente, se mencionan las tasas retributivas que ya estaban reglamentadas en los artículos 42 y 43 de la Ley 99 de 1993, las cuales son mencionadas en el artículo 11 de Decreto 1220 y presentadas por la Tabla 16.

Tabla 16. Análisis comparativo entre el Decreto 1180 de 2003 y el Decreto 1220 de 2005. Fuente: Elaboración propia

\begin{tabular}{|c|c|}
\hline Decreto 1180 de 2003 & Decreto 1220 DE 2005 \\
\hline $\begin{array}{l}\text { Artículo 12. Definición de } \\
\text { competencias. Cuando el } \\
\text { proyecto, obra o actividad se } \\
\text { desarrolle en jurisdicción de } \\
\text { dos o más autoridades } \\
\text { ambientales, el Ministerio de } \\
\text { Ambiente, Vivienda y } \\
\text { Desarrollo Territorial, designará } \\
\text { la autoridad ambiental } \\
\text { competente para el } \\
\text { otorgamiento de la licencia } \\
\text { ambiental. }\end{array}$ & $\begin{array}{l}\text { Artículo 11. Definición de } \\
\text { competencias. Cuando el } \\
\text { proyecto, obra o actividad se } \\
\text { desarrolle en jurisdicción de } \\
\text { dos o más autoridades } \\
\text { ambientales, el Ministerio de } \\
\text { Ambiente, Vivienda y } \\
\text { Desarrollo Territorial, designará } \\
\text { la autoridad ambiental } \\
\text { competente para decidir sobre } \\
\text { el otorgamiento de la licencia } \\
\text { ambiental. }\end{array}$ \\
\hline
\end{tabular}


Ing. USBMed, Vol. 7, No. 1, Enero-Julio 2016 la licencia ambiental, se participación de cada entidad en el proceso de seguimiento, evaluación y control del cumplimiento de los términos, condiciones y obligaciones contenidos en ella
En el acto de otorgamiento de precisará la forma de

\begin{abstract}
En el acto de otorgamiento de la misma, la autoridad designada precisará la forma de participación de cada entidad en el proceso de seguimiento. En todo, caso, una vez otorgada la licencia ambiental, el beneficiario deberá cancelar las tasas ambientales a la autoridad ambiental en cuya jurisdicción se haga el uso, aprovechamiento $\quad \mathrm{y} / \mathrm{o}$ vertimiento respectivo. Lo anterior sin perjuicio de lo dispuesto en el inciso segundo del artículo 66 de la Ley 99 de 1993.
\end{abstract}

Dichas tasas consisten en el pago por el uso y/o aprovechamiento de los recursos naturales, este tema se reafirma en el Decreto 1180 de 2003. Es importante la implantación de estas tasas para que así las personas tomen conciencia del valor de los recursos y la necesidad de contribuir a su recuperación.

En cuanto a los tiempos, se da un aumento en el plazo que tiene la autoridad para definir cuando un proyecto requiere DAA, mientras en el decreto 1180 de 2003 el tiempo era de 10 días, para el momento de entrada en vigencia del 1220 de 2005, este tiempo cambia a 15 días.

Como se mencionó inicialmente, más que cambios, lo que se generó con la promulgación del 1220 fue enfatizar y adicionar información que otorgó claridad en muchos procedimientos y en ocasiones aumentó los requerimientos para lograr una mejor gestión.

Dos temas son nuevos en el 1220 de 2005, que permiten una fluidez en el procedimiento y la posibilidad de que la comunidad esté más informada sobre los proyectos que están en proceso de licenciamiento; uno de ellos es el Sistema de Información Ambiental, el cual es un conjunto de bases de datos estadísticos, cartográficos y documentales que recopilan, organizan y difunden la información acerca del ambiente y los recursos naturales del país [...], facilitando así las labores de las autoridades y permitiendo que todas las personas puedan obtener información sobre los proyectos en curso y los trámites de las licencias y los PMAs.

Además en el artículo 40 de éste decreto se comienza a exigir a todos los proyectos anteriores a la promulgación de ese decreto que no tengan licencia ambiental, la presentación de un PMA para conocer las afectaciones de cada proyecto y su manera de controlarlas, lo cual se constituye en una avance para la gestión y conservación del medio ambiente.

Finalmente, se observa que en el artículo 5 el Decreto 1220 hace omisión a una información que resulta importante, la cual sí es mencionada en el parágrafo del artículo 5 del 1180, el cual dice: "En ningún caso las autoridades ambientales podrán otorgar licencias, permisos, concesiones 0 autorizaciones de orden ambiental, para obras y trabajos no amparados por un título minero, conforme al inciso segundo del artículo 195 de la Ley 685 de 2001."

\subsection{Decreto 1220 de 2005 en comparación con el Decreto 2820 de 2010}

El decreto 2820 de 2010 es la quinta norma expedida sobre licencias ambientales, desde el año 1994. Esto para muchos es un claro mensaje de que en Colombia hay una inestabilidad jurídica en esta área en particular, como quiera que se cambian 0 modifican permanentemente las normas sobre un tema tan importante para la gestión ambiental y el desarrollo económico del país como son las Licencias Ambientales.

En el año 2010, con la expedición del Decreto 2820 hubo un avance "positivo" en cuanto a las precauciones ambientales y las acciones a llevar a cabo durante las etapas de planeación y ejecución de proyectos a desarrollar en el territorio colombiano.

Algunos de los cambios más relevantes, que pueden ser apreciados en el Decreto 2820 de 2010 se enuncian a continuación:

El parágrafo 1 del artículo 8, le resta aplicabilidad a la licencia ambiental global, al enunciar que proyectos relacionados a la explotación de hidrocarburos que hayan solicitado una licencia para la exploración de cierta área, solo requiere de una modificación de la misma, para ejecutar la explotación del área.

Se incluyeron conceptos importantes dentro del artículo dedicado a definiciones; por ejemplo: se introdujo el concepto de explotación minera y contingencia ambiental.

Se obligó a que quien ejecute el proyecto, tenga en cuenta dentro del estudio de impacto ambiental cuál será realmente el uso y la afectación que tendrán los recursos naturales renovables involucrados.

Las CAR tienen imposibilidad de aprobar permisos, ajustes 0 concesiones a proyectos previamente aprobados por el ministerio de ambiente, vivienda y desarrollo territorial.

Delimitó el alcance y el objeto de la licencia ambiental Global.

Se presentaron cambios en cuanto a la competencia del Ministerio de Medio Ambiente, para reservarse el derecho de otorgar licencias ambientales a proyectos de los sectores: hidrocarburos, minería, sector eléctrico, de energía nuclear, producción de pesticidas y en la construcción de aeropuertos. 
Se definió que la licencia ambiental es prerrequisito para el otorgamiento de concesiones portuarias, al igual que se expresó claramente, que la modificación de la misma, es una condición previa para ejercer los derechos derivados de la modificación de un permiso, autorización concesión, contrato o licencia ambiental expedido por autoridades diferentes a las ambientales.

Un cambio importante y que fue un gran complemento en el Decreto 2820 es la obligación de realizar ajustes en la licencia ambiental, en aquellos casos donde la autoridad competente, encuentre evidencia de impactos derivados por la ejecución del proyecto, y que no estaban identificados o descritos desde el momento de la solicitud de la licencia.

El Nuevo Decreto 2820 de 2010, brinda la posibilidad de integrar licencias ambientales solicitadas para diferentes etapas de un proyecto.

4. Se incluyeron razones por las cuales podría ser modificada una licencia ambiental. En la Tabla 17 se comparan el artículo 26 del decreto 1220 de 2005 y el artículo 29 del decreto 2820 de 2010. Cambios del 2041 respecto a los decretos analizados en el capítulo 3

Este decreto se ha destacado por estar en boca de los críticos ambientalistas incluso antes de que fuera sancionado por el ejecutivo, pues los proyectos u obras que pretende reglamentar este decreto, pueden vulnerar la sostenibilidad ambiental del territorio colombiano en contra de la protección del medio ambiente y en aras de poder garantizar un mejor futuro a nuestras próximas generaciones.

Como ejemplo de esto encontramos las siguientes particularidades en la citada norma:

En el artículo 8 de los decretos 2820 de 2010 y 2041 de 2014, el cual tiene como fin el denegar u otorgar la licencia ambiental, en la Tabla 18 se observa como la norma se flexibiliza con el nuevo decreto.

En este caso se evidencia que la actual norma es menos exigente pues en el pasado decreto la capacidad reglamentada era de $3 \mathrm{MW}$ y pasa a $100 \mathrm{MW}$, un aumento considerable en la regulación de la producción de energía alternativa como si la proliferación de éstas en determinadas circunstancias no constituyeran en sí mismas un posible riesgo ambiental.

Por su parte, en la regulación de los dragados de profundización de canales de acceso a puertos marítimos de gran calado, se evidencia un retroceso, porque desaparece de la reglamentación la figura del mantenimiento y la medición del volumen, donde ésta última ayudaba a definir el concepto de puerto marítimo de gran calado, esta medición desaparece del Decreto 2041 y deja inconclusa esta definición.

Tabla 17. Análisis comparativo entre el Decreto 1220 de 2005 y Decreto 2820 de 2010. Fuente: Elaboración propia

\begin{tabular}{ll}
\hline Decreto 1220 de 2005 & Decreto 2820 de 2010 \\
\hline $\begin{array}{c}\text { Artículo 26. Modificación de la } \\
\text { licencia ambiental. La Licencia }\end{array}$ & $\begin{array}{l}\text { Artículo 29. Modificación de la } \\
\text { licencia ambiental. La Licencia }\end{array}$ \\
$\begin{array}{c}\text { Ambiental podrá ser modificada } \\
\text { en los siguientes casos: }\end{array}$ & $\begin{array}{l}\text { Ambiental podrá ser modificada } \\
\text { en los siguientes casos: }\end{array}$ \\
\hline $\begin{array}{l}\text { 1. En consideración a la } \\
\text { variación de las condiciones }\end{array}$ & $\begin{array}{l}\text { Licencia Ambiental pretenda } \\
\text { modificar el proyecto, obra o }\end{array}$ \\
existentes al momento de to ditular la Licencia Ambiental. & $\begin{array}{l}\text { actividad de forma que se } \\
\text { generen impactos ambientales } \\
\text { adicionales a los ya } \\
\text { identificados en la licencia } \\
\text { ambiental; }\end{array}$ \\
\hline
\end{tabular}

2. Cuando al otorgarse la Licencia Ambiental no se contemple el uso, aprovechamiento o afectación de los recursos naturales renovables, necesarios 0 suficientes para el buen desarrollo y operación del proyecto, obra o actividad.

3. Cuando se pretendan variar las condiciones de uso, aprovechamiento o afectación de un recurso natural renovable, consagradas en la Licencia Ambiental.

2. Cuando al otorgarse la Licencia Ambiental no se contemple el uso, aprovechamiento o afectación de los recursos naturales renovables, necesarios 0 suficientes para el buen desarrollo y operación del proyecto, obra o actividad

3. Cuando se pretendan variar las condiciones de uso, aprovechamiento o afectación de un recurso natural renovable, de forma que se genere un mayor impacto sobre los mismos respecto de lo consagrado en la licencia ambiental.

5. Cuando el proyecto, obra o actividad cambie de autoridad ambiental competente por efecto de un ajuste en el volumen de explotación, el calado, la producción, el nivel de tensión y demás características del proyecto;

6. Cuando como resultado de las labores de seguimiento, la autoridad identifique impactos ambientales adicionales a los identificados en los estudios ambientales y requiera al licenciatario para que ajuste tales estudios.

7. Cuando las áreas objeto de licenciamiento ambiental no hayan sido intervenidas y éstas áreas sean devueltas a la autoridad competente por parte de su titular.

8. Cuando se pretenda integrar la licencia ambiental con otras licencias ambientales.

\footnotetext{
Tabla 18. Análisis comparativo entre el Decreto 1180 de 2003 y el Decreto 1220 de 2005. Fuente: Elaboración propia
}

Decreto 2820 de 2010 


\begin{tabular}{|c|c|}
\hline 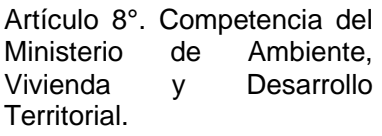 & $\begin{array}{l}\text { Artículo } 8^{\circ} \text {. } \text { Competencia de la } \\
\text { Autoridad } \\
\text { Licencias } \\
\text { (ANLA) Ambientales } \\
\end{array}$ \\
\hline $\begin{array}{l}\text { b) Los proyectos de } \\
\text { exploración y uso de fuentes } \\
\text { de energía alternativa } \\
\text { virtualmente contaminantes } \\
\text { con capacidad instalada } \\
\text { superior a 3MW; }\end{array}$ & $\begin{array}{l}\text { b) Los proyectos de } \\
\text { exploración y uso de fuentes } \\
\text { de energía alternativa } \\
\text { virtualmente contaminantes } \\
\text { con capacidad instalada } \\
\text { superior o igual cien (100) } \\
\text { MW', }\end{array}$ \\
\hline
\end{tabular}

\begin{tabular}{|c|c|}
\hline $\begin{array}{l}\text { b) Los dragados de } \\
\text { profundización de los canales } \\
\text { de acceso a puertos } \\
\text { marítimos de gran calado y } \\
\text { los de mantenimiento cuyo } \\
\text { volumen sea superior a } \\
1000.000 \text { de m3/año; }\end{array}$ & $\begin{array}{l}\text { b) Los dragados de } \\
\text { profundización de los canales } \\
\text { de acceso a puertos } \\
\text { marítimos de gran calado; }\end{array}$ \\
\hline $\begin{array}{l}\text { b) La construcción de } \\
\text { segundas calzadas; }\end{array}$ & $\begin{array}{l}\text { b) La construcción de } \\
\text { segundas calzadas; salvo lo } \\
\text { dispuesto en el parágrafo } 2 \\
\text { del artículo } 1^{\circ} \text { del Decreto } 769 \\
\text { de } 2014\end{array}$ \\
\hline
\end{tabular}

Finalmente, en el tema de construcción de segundas calzadas o de un carril adicional en las ya existentes en la categoría de red vial que establece el ministerio de transporte como; primaria, secundaria y terciaria, el actual decreto adiciona la excepción de salvo lo dispuesto en el parágrafo 2, artículo 1 del decreto 769 de 2014, el cual establece lo siguiente "Parágrafo 2.(...) las segundas calzadas podrán ser consideradas como actividades de mejoramiento, en aquellos eventos en que la autoridad ambiental así lo determine. Para el efecto, el titular deberá allegar ante la autoridad ambiental competente un documento en el que de acuerdo con los impactos que éste pueda generar, justifique las razones por las cuales la ejecución del mismo no genera deterioro grave a los recursos naturales renovables o al medio ambiente o introducir modificaciones considerables o notorias al paisaje. La autoridad ambiental en un término máximo de veinte (20) días hábiles contados a partir de la radicación de la solicitud deberá emitir, mediante oficio, el correspondiente pronunciamiento." Esto genera un deterioro en la regulación ambiental, mucho más cuando el país atraviesa por una fase de transformación en la infraestructura vial, con grandes inversiones que ameritan un cuidado especial al momento de su ejecución.

En el artículo 8 del Decreto 2041 de 2014, se reglamenta la intervención en los parques naturales previo al otorgamiento de la licencia ambiental, por parte del mismo Ministerio del Medio Ambiente y Desarrollo Sostenible. Esta reglamentación sobre los proyectos que afectaran el Sistema de Parques Nacionales Naturales no es nueva, ya que como es el caso del Decreto 1753 de 1994, artículo 4 numeral 9 también se reglamentaba; la Tabla 19 muestra los cambios que se realizaron.
En este numeral observamos que se introduce la construcción de infraestructura al interior de los parques, siempre y cuando estos sean compatibles con los usos establecidos, y entre estos encontramos en el artículo 34 del Decreto 2372 de 2010 en el cuarto inciso una "zona de uso sostenible" como espacios para adelantar actividades productivas y extractivas, y a su vez este inciso establece una "subzona para el desarrollo, en cual se define de la siguiente manera: "Son espacios donde se permiten actividades controladas, agrícolas, ganaderas, mineras, forestales, industriales, habitacionales no nucleadas con restricciones en la densidad de ocupación y la construcción y ejecución de proyectos de desarrollo, bajo un esquema compatible con los objetivos de conservación del área protegida". Queda abierta la posibilidad de que estos espacios puedan ser intervenidos, lo cual genera un retroceso con respecto a normatividades anteriores.

En el artículo 29 que reglamenta la modificación de la licencia ambiental, el Decreto 2041 de 2014 presenta una transformación respecto al Decreto 2820 de 2010 en que se le agrega un numeral, el cual factiblemente deja abierta la posibilidad de practicar el fracking por medio de la explotación de yacimientos no convencionales, todo lo cual debe ser considerado al momento de realizarse los debates sobre este tipo de tecnología y sus posibles impactos ambientales. Esto se puede hacer, siempre y cuando en un principio los peticionarios presenten una solicitud de licencia ambiental con un Plan de Manejo Ambiental que incluya esta modalidad. Esta información es presentada por la Tabla 20, donde se compara el artículo 29 de ambos decretos. 
Tabla 19. Análisis comparativo entre el Decreto 2820 de 2010 y el Decreto 2041 de 2014. Fuente: Elaboración propia

\begin{tabular}{|c|c|}
\hline Decreto 2820 de 2010 & Decreto 2041 de 2014 \\
\hline $\begin{array}{l}\text { Artículo } 8^{\circ} \text {. Competencia del } \\
\text { Ministerio de Ambiente, } \\
\text { Vivienda y Desarrollo } \\
\text { Territorial. } \\
\text { 13. Los proyectos, obras o } \\
\text { actividades a realizarse al } \\
\text { interior de las áreas protegidas } \\
\text { públicas nacionales de que } \\
\text { trata el Decreto } 2372 \text { del } 1^{\circ} \text { de } \\
\text { julio de } 2010 \text {, distintos a los } \\
\text { enunciados en el numeral } \\
\text { anterior, siempre que el uso sea } \\
\text { permitido de acuerdo a la } \\
\text { categoría de manejo respectiva } \\
\text { e impliquen la construcción de } \\
\text { infraestructura en las zonas de } \\
\text { uso sostenible y general de uso } \\
\text { público, o se trate de proyectos } \\
\text { de agroindustria, a excepción } \\
\text { de las unidades habitacionales, } \\
\text { siempre que su desarrollo sea } \\
\text { compatible con los usos } \\
\text { definidos. }\end{array}$ & $\begin{array}{l}\text { Artículo } 8^{\circ} \text {. Competencia de la } \\
\text { Autoridad Nacional de } \\
\text { Licencias Ambientales (ANLA). } \\
\text { 13. Los proyectos, obras o } \\
\text { actividades de construcción de } \\
\text { infraestructura o agroindustria } \\
\text { que se pretendan realizar en las } \\
\text { áreas protegidas públicas } \\
\text { nacionales de que trata el } \\
\text { Decreto } 2372 \text { de } 2010 \text { distintas } \\
\text { a las áreas de Parques } \\
\text { Nacionales Naturales, siempre } \\
\text { y cuando su ejecución sea } \\
\text { compatible con los usos } \\
\text { definidos para la categoría de } \\
\text { manejo respectiva. Lo anterior } \\
\text { no aplica a proyectos, obras o } \\
\text { actividades de infraestructura } \\
\text { relacionada con las unidades } \\
\text { habitacionales y actividades de } \\
\text { mantenimiento y rehabilitación } \\
\text { en proyectos de infraestructura } \\
\text { de transporte de conformidad } \\
\text { con lo dispuesto en el artículo } \\
44 \text { de la Ley } 1682 \text { de } 2013 \text {, } \\
\text { salvo las actividades de } \\
\text { mejoramiento de acuerdo con } \\
\text { lo dispuesto el artículo } 4^{\circ} \text { del } \\
\text { Decreto } 769 \text { de } 2014 .\end{array}$ \\
\hline
\end{tabular}

\begin{abstract}
Tabla 20. Análisis comparativo entre el Decreto 2820 de 2010 y el Decreto 2041 de 2014. Fuente: Elaboración propia
\end{abstract}

\begin{tabular}{ll}
\hline Decreto 2820 de 2010 & Decreto 2041 de 2014 \\
\hline $\begin{array}{l}\text { Artículo 29. Modificación de } \\
\text { la Licencia Ambiental. }\end{array}$ & $\begin{array}{l}\text { Artículo 29. Modificación de la } \\
\text { Licencia Ambiental. }\end{array}$
\end{tabular}

9. Para el caso de proyectos existentes de exploración y/o explotación de hidrocarburos en yacimientos convencionales que pretendan también desarrollar actividades de exploración y explotación de hidrocarburos en yacimientos no convencionales siempre y cuando se pretenda realizar el proyecto obra o actividad en la misma área ya licenciada y el titular sea el mismo, de lo contrario requerirá adelantar el proceso de licenciamiento ambiental de que trata el artículo 25. Este numeral no aplica para los proyectos que cuentan con un plan de manejo ambiental como instrumento de manejo y control, caso en el cual se deberá obtener la correspondiente licencia ambiental.

Frente a este tema se pueden levantar muchas controversias y más cuando el 26 de marzo de 2014 la
Agencia Nacional de Hidrocarburos (ANH) expidió la reglamentación de contratación para la explotación y exploración de hidrocarburos en yacimientos no convencionales en un claro intento de reglamentar esta práctica.

Respecto a los tiempos, en el artículo 31 del Decreto 2041 se observa que la autoridad ambiental competente tiene que expedir el acto de inicio de trámite inmediatamente se radica la solicitud de la modificación de la Licencia Ambiental, mientras que, según lo expuesto en el Decreto 2820 de 2010 se contaba con 5 días para hacerlo y si se remonta más atrás en el tiempo, en el Decreto 1753 de 1994, la autoridad Ambiental contaba con 30 días hábiles para pronunciarse.

Otra deficiencia que se encuentra en este análisis, en el artículo 25 Decreto 2041, se reglamenta opcionalmente la no visita y en este caso la autoridad ambiental competente dispondrá de 10 días hábiles para realizar la reunión con el fin de solicitar por única vez información adicional, y toda decisión que se adopte en esta reunión se notificará verbalmente, (clara evidencia de pérdida de rigurosidad) al solicitante o representante legal en caso de ser persona jurídica.

Respecto al artículo 41 comparado con su par del Decreto 2820, el segundo inciso de este artículo dice que la autoridad ambiental competente determinará sobre la necesidad de verificar los hechos para imponer medidas adicionales si es del caso y el hecho de que la autoridad ambiental determine si es necesario verificar los hechos. Esto hace que la norma sea flexible, porque primero no se tiene especificado qué aspectos debe tener una contingencia para ser medida como grave 0 no, y segundo es que hay una gran posibilidad de que la autoridad ambiental no verifique por sí misma.

Pero no todo en este decreto ha sido un retroceso, también se encontraron avances respecto a las normas que la precedieron, como en el artículo 21, el cual establece lo que debe contener el EIA en donde el numeral 3 le adiciona y reglamenta la recolección de especímenes de diversidad biológica con fines no comerciales.

Adicional a esto, en el artículo 5, segundo inciso, manifiesta que la licencia ambiental es prerrequisito para el otorgamiento de concesiones portuarias, pero la mejora no está allí, está en que la norma lo especifica conforme a lo dispuesto en el parágrafo 1, artículo 52 de la Ley 99 de 1993, puesto que ésta dicta que la facultad de otorgar la licencia ambiental se hará sin perjuicio de la competencia legal de la Superintendencia general de puertos de otorgar concesiones portuarias.

Como se puede observar en la Tabla 21, en la evaluación del EIA se evidencia una ambigüedad, porque por un lado en su parágrafo 5 se le adiciona 
información que el decreto antecesor no la tenía, pero al mismo tiempo, este parágrafo le da la posibilidad que la veda se levante y de esta manera la autoridad ambiental pueda expedir el acto administrativo que declare reunida toda la información requerida así como para expedir la resolución que otorga o niega la licencia ambiental cuando el solicitante allegue copia de los actos administrativos, a través de los cuales se concede la sustracción o el levantamiento de la veda.

Tabla 21. Análisis comparativo entre el Decreto 2820 de 2010 y el Decreto 2041 de 2014. Fuente: Elaboración propia

\begin{tabular}{ll}
\hline Decreto 2820 de 2010 & Decreto 2041 de 2014 \\
\hline $\begin{array}{l}\text { Artículo 25. De la evaluación } \\
\text { del estudio de impacto } \\
\text { ambiental }\end{array}$ & $\begin{array}{l}\text { Artículo 25. De la evaluación } \\
\text { del estudio de impacto } \\
\text { ambiental }\end{array}$ \\
& $\begin{array}{l}\text { Parágrafo } 5^{\circ} \text {. Cuando el } \\
\text { proyecto, obra o actividad } \\
\text { requiera la sustracción de un } \\
\text { área de reserva forestal o el } \\
\text { levantamiento de una veda, la } \\
\text { autoridad ambiental no podrá } \\
\text { dar aplicación al numeral } 5^{\circ} \text { del } \\
\text { presente artículo hasta tanto el } \\
\text { solicitante allegue copia de los } \\
\text { actos administrativos, a través } \\
\text { de los cuales se concede la } \\
\text { sustracción o el levantamiento } \\
\text { de la veda. }\end{array}$ \\
\hline
\end{tabular}

Por último encontramos como aspecto positivo, que frente a la información ambiental para la toma de decisiones, artículo 40, se presenta la adición de dos parágrafos, en el cual el primero se busca recolectar información para establecer una zonificación ambiental y poner ésta disposición en el portal web de la ANLA a cualquier ciudadano.

\section{Conclusiones}

Debido a tantos cambios que se han producido durante estos últimos años, es evidente que actualmente los requerimientos del licenciamiento ambiental, han ido disminuyendo de manera progresiva el nivel de restricciones y condicionantes para el solicitante, hasta llegar al punto de acortar los tiempos de estudio previo y flexibilizar la rigurosidad con la que se evalúan los mismos; todo esto conlleva a que no se realice una evaluación minuciosa y crítica de los estudios, porque las autoridades no cuenta con el recurso técnico y humano adecuado que permita la integración de conocimientos interdisciplinarios que posibiliten un análisis juicioso de los diferentes aspectos de los proyectos.

El hecho de flexibilizar las licencias ambientales implica muchas veces un retroceso injustificado en la protección ambiental; y que es deber del Estado tomar medidas que contribuyan a una evolución de la legislación, situación que no se identifica en los temas de licenciamiento, porque a medida que se crea una nueva norma su objetivo está encaminado a una interrupción o devolución injustificada en la legislación.

En materia ambiental, nuestra constitución tiene como pilares en el título II, capítulo III que nos habla de los derechos colectivos y del medio ambiente, los principios de planificación, pues dice que garantizará su desarrollo sostenible, su conservación, restauración o sustitución. Estos principios se ven afectados por la manera como se ha venido desarrollando.

El hecho de reducir los tiempos durante el proceso de licenciamiento ambiental, puede comprometer la revisión y análisis mismo de los documentos presentados en los Estudios de Impacto Ambiental, en la búsqueda de una eficiencia administrativa que no necesariamente significa una adecuada conceptualización y evaluación por parte de la autoridad ambiental de los documentos entregados, todo lo cual puede comprometer hacia el futuro la gestión adecuada de los recursos naturales y el ambiente.

\section{Trabajos futuros}

Esta investigación origina una línea de análisis profundo, sobre las modificaciones efectuadas en la legislación ambiental colombiana desde sus inicios.

Se estudia y critica, la evolución de los requisitos y procedimientos asociados a la solicitud de las licencias ambientales, desde la promulgación de la Ley 99 de 1993 hasta el actual decreto, el 2041 del año 2014.

La información obtenida como producto de esta investigación, servirá para analizar los posibles en escenarios en los que el país estuviese envuelto, si no se hubiesen efectuado los cambios pasados en la legislación, al igual que las posibles implicaciones, de mantener la legislación ambiental en el estado actual.

Otro proyecto que puede surgir a partir del análisis de la información presentada en esta investigación, es la creación de una guía metodológica para cada sector de la industria, en la cual se presente un paso a paso de los aspectos a considerar en la realización de estudios y planes asociados a la solicitud de una licencia ambiental, destacando la importancia de realizar adecuadamente lo expuesto en el decreto vigente.

Por otra parte, también sería bueno llevar a cabo un análisis detallado, sobre el riesgo económico, financiero y penal en él puede verse involucrada una empresa y sus representantes al intentar evadir la normatividad ambiental vigente y la posible sanción asociada. Siendo bastantes profundos en la comparación de los beneficios del "actuar legal" vs las implicaciones del "actual ilegal".

\section{Referencias}

[1] G. A. Rodriguez, "Las licencias ambientales y su proceso de reglamentación en Colombia,» Bogotá, 2011. 
[2] Revista Semana, «Semana Sostenible,» Publicaciones Semana SA, 26 Septiembre 2014. [En línea]. Available: http://sostenibilidad.semana.com/medioambiente/articulo/desarrollo-sostenible-expres/31893. [Último acceso: 15 Febrero 2015].

[3] Departamento Nacional de Planeación, «Evaluación de operaciones al proceso de licenciamiento ambiental en sus etapas de planeación, evaluación y seguimiento, desarroolladas por las entidades encargadas del sector, los peticionnarios y las autoridades ambientales., " Union temporal SEI sa y Fundación Natura., Bogotá, 2013.

[4] A. Viana, «Red por la justicia ambiental en Colombia,» Port Bou, 24 Septiembre 2014. [En línea]. Available: http://justiciaambientalcolombia.org/2014/09/24/a-proposito-delas-licencias-expres/. [Último acceso: 15 Diciembre 2014].

[5] Revista Semana, «Semana,» Publicaciones Semana sa, 27 Septiembre 2014. [En línea]. Available: http://www.semana.com/nacion/articulo/que-pasa-con-laslicencias-ambientales-expres/404177-3. [Último acceso: 15 Diciembre 2014].

[6] Colprensa, «El País,» El País sa, 25 Septiembre 2014. [En línea].

Available: http://www.elpais.com.co/elpais/colombia/noticias/senadorrobledo-realizara-debate-contra-licencias-ambientales-expres. [Último acceso: 15 Diciembre 2014].

[7] C. d. Colombia, «Alcaldía de Bogotá,» 8 Agosto 2001. [En línea]. Available:

http://www.alcaldiabogota.gov.co/sisjur/normas/Norma1.jsp?i=9 202. [Último acceso: 12 Enero 2015].

[8] C. d. Colombia, «Alcaldía de Bogotá,» 3 Agosto 1994. [En línea]. Available:

http://www.alcaldiabogota.gov.co/sisjur/normas/Norma1.jsp?i=1 299. [Último acceso: 20 Noviembre 2014].
[9] P. d. I. R. d. Colombia, «Alcaldía de Bogotá,» 6 Agosto 2002. [En línea]. Available: http://www.alcaldiabogota.gov.co/sisjur/normas/Norma1.jsp?i=5 548. [Último acceso: 20 Noviembre 2014].

[10] P. d. I. R. d. colombia, «Alcaldía de Bogotá,» 10 Mayo 2003. [En línea]. Available: http://www.alcaldiabogota.gov.co/sisjur/normas/Norma1.jsp?i=8 144. [Último acceso: 28 Noviembre 2014].

[11] P. d. I. R. d. Colombia, «Alcaldía de Bogotá,» 21 Abril 2005. [En línea]. Available: http://www.alcaldiabogota.gov.co/sisjur/normas/Norma1.jsp?i=1 6316. [Último acceso: 28 Noviembre 2014].

[1] P. d. I. R. d. Colombia, «Alcaldía de Bogotá,» 5 Agosto 2010. [En línea]. Available: http://www.alcaldiabogota.gov.co/sisjur/normas/Norma1.jsp?i=4 5524. [Último acceso: 4 Diciembre 2014].

[13] P. d. I. R. d. Colombia, "Ministerio del Medio Ambiente y Desarrollo Sostenible,» 15 Octubre 2014. [En línea]. Available: https://www.minambiente.gov.co/images/normativa/app/decreto $\mathrm{s} / 34-$ DECRETO\%202041\%20DEL\%2015\%20DE\%200CTUBRE\%2 0DE\%202014.pdf. [Último acceso: 4 Diciembre 2014].

[14] P. d. I. R. d. Colombia, "Ministerio del Medio Ambiente y Desarrollo Sostenible,» 1 Julio 2010. [En línea]. Available: https://www.minambiente.gov.co/images/normativa/decretos/20 10/dec_2372_2010.pdf. [Último acceso: 16 Enero 2015].

[15] A. N. d. Hidrocarburos, «Red Por la Justicia Ambiental en Colombia,» 26 Marzo 2014. [En línea]. Available: https://redjusticiaambientalcolombia.files.wordpress.com/2014/0 9/terminos_no-convencionales.pdf. [Último acceso: 16 Enero 2015] 